but by no means for heating or the industrial demands for electrothermal and chemical needs.

The experience of the First World War stimulated the development of hydro-electric resources and the use of electricity for railways, lighting, power and special heating, where it offered a preponderating advantage. It could only be used in summer for general heating and for electrochemical or electrometallurgical purposes. By 1938, 98 per cent of the railway traffic was electrically operated, but electricity provided 5 per cent only of the total supply of thermal energy. Three-quarters of the heat was supplied by imported coal. Moreover, between 1913 and 1938 the consumption of coal altered little. There was only a change in the distribution of the load.

When war broke out in 1939 it was not surprising that rationing became drastic and realistic. All production of electricity by fuel-fired boilers-except back-pressure units-was suspended. Coal was allocated according to priorities. Domestic heating, which in 1938 absorbed 50 per cent of the imports of coal, was 'mercilessly' cut to nil in 1943-44, and gas to 21 per cent in 1945-46. In winter, electricity would be prohibited for space heating, water heating and steam generation, these being termed 'lowefficiency uses' of electricity. Industrial coal-fired boiler plant offered little scope for fuel saving, owing to the high efficiencies current in peace-time. To meet the high cost of fuel, boiler efficiencies of 75-80 per cent were the rule, even in small plants. Figures such as these are uncommon in Great Britain.

In conclusion, the report says that in spite of the abundance of water-power, half of which is already developed, Switzerland remains dependent on imported coal. There need be no illusions of its replacement by hydro-electric power. The supply of electricity is limited by natural causes. Its proper application is the supply of power, and in winter its use for low-grade heating is not encouraged.

\section{NEW ITALIAN COSMIC RAY LABORATORY}

A NEW high-altitude research laboratory for cosmic ray work at a height of $11,500 \mathrm{ft}$. on the upper slopes of Monte Rosa was opened by the Italian Centre for Research in Nuclear Studies on January 11. The laboratory portion of the station at present consists of one large experimental room, and a small fully screened room for a Wilson cloud chamber. The equipment is very complete, and includes a three-phase $30 \mathrm{~kW}$. power supply, a separate lighting supply, and two high-capacity battery sets with a petrol generator in case of main power failure. The station is also equipped for twoway direct radio contact with the parent laboratory at Rome, a useful facility at all times, but particularly necessary when the Laboratory is likely to be cut off from the outside world for days at a time in midwinter.

The Laboratory is situated on an exposed ridge on the Italo-Swiss frontier, and is actually half in Switzerland. It is served by a cable railway, which - under normal weather conditions-runs from Breuil (Cervinia) in the valley, 4,500 ft. below. Breuil is itself connected with the rail-head at Chatillon by a road which is kept open throughout the winter. The problems of supply are, therefore, very much less than might reasonably be expected at such an altitude.

At the present moment, the Laboratory has living accommodation for four workers, with bunks, a small kitchen and bathroom. Water is obtained by melting snow with an immersion heater, the water then being pumped to a roof-tank. Waste disposal is by a double-walled heated pipe. The building itself is of aluminium and cork construction, and is securely anchored against the high winds which sweep the ridge.

The work at present going on in the Laboratory includes the exposure of nuclear plates, which in suitable weather can also be carried out up to $3,000 \mathrm{ft}$. above the Laboratory. Experiments on meson decay are also being carried on, and it is expected that later some Italian geneticists will be undertaking work at the station on mutations induced by cosmic rays. The director of the Laboratory is Prof. Gilberto Bernadini, who, with the director of the Centre for Research in Nuclear Studies, Prof. Edoardo Amaldi, is already well known in Britain for his work in this field. It is expected that at least one British physicist will be working at the Laboratory in the near future.

The inauguration ceremony was performed by Minister of the Treasury, Del Vecchio, in the presence of some sixty distinguished Italian scientific workers, and representatives of various industrial firms and the Italian Air Ministry. At the invitation of Profs. Bernadini and Amaldi, British science was represented by Dr. Tahourdin, science officer in Italy of the British Council.

\section{VETERINARY EDUCATIONAL TRUST}

HE Veterinary Educational Trust was formed in 1942 , to provide for the education of graduate and postgraduate students of the best type who would not otherwise be able to proceed with their studies; means were to be found to ensure that training was provided of a type not otherwise available in Great Britain, so that veterinarians and other men of science would be equipped to undertake original research.

In the course of the ensuing years, it has been found that the original aims require to be extended. It has been decided to embark upon a plan to develop research stations dealing with the management and diseases of the different species of domesticated animals. An Equine Research Station at Balaton Lodge and Lanwades Park near Newmarket (director, Prof. W. C. Miller), a Canine Research Station (director, Mr. S. F. J. Hodgman), and also a Poultry Research Station (director, Dr. R. F. Gordon) have been opened; all these directors are veterinary surgeons.

A group of farm livestock research stations will be opened; negotiations are in progress for sites for such work. All these stations will be established within a few miles of each other and of the University of Cambridge. In developing these centres, care is being taken to ensure that there is close contact between them and the workers in the field, and there will be close co-operation with practising veterinary surgeons. The research stations will link up with a series of hospitals for large and small animals, and there will be joint laboratory diagnostic service. The aim will be to have a hospital in every county and in the larger towns. 